\title{
Cesàro summable difference sequence space
}

\author{
Vinod K Bhardwaj ${ }^{1 *}$ and Sandeep Gupta ${ }^{2}$
}

*Correspondence: vinodk_bhj@rediffmail.com

'Department of Mathematics, Kurukshetra University, Kurukshetra, 136119, India

Full list of author information is available at the end of the article

\begin{abstract}
The difference sequence spaces $c_{0}(\Delta), c(\Delta)$ and $\ell_{\infty}(\Delta)$ were introduced by Kizmaz (Can. Math. Bull. 24:169-176, 1981). In this paper, we introduce the Cesáro summable difference sequence space $C_{1}(\Delta)$ which strictly includes the spaces $c_{0}(\Delta)$ and $c(\Delta)$ but overlaps with $\ell_{\infty}(\Delta)$. It is shown that the newly introduced space $C_{1}(\Delta)$ turns out to be an inseparable BK space which does not possess any of the following: AK property, monotonicity, normality and perfectness. The Köthe-Toeplitz duals of $C_{1}(\Delta)$ are computed and as an application, the matrix classes $\left(C_{1}(\Delta), \ell_{\infty}\right),\left(C_{1}(\Delta), C_{i} P\right)$ and $\left(C_{1}(\Delta), C_{0}\right)$ are also characterized.

MSC: 40C05; 40A05; 46A45
\end{abstract}

Keywords: sequence space; BK space; Schauder basis; Köthe-Toeplitz duals; matrix map

\section{Notations and definitions}

By $s$ we shall denote the linear space of all complex sequences over $\mathbb{C}$ (the field of complex numbers). $\ell_{\infty}, c$ and $c_{0}$ denote the spaces of all bounded, convergent and null sequences $x=\left(x_{k}\right)$ with complex terms, respectively, normed by $\|x\|_{\infty}=\sup _{k}\left|x_{k}\right|$.

Throughout this paper, unless otherwise specified, we write $\sum_{k}$ for $\sum_{k=1}^{\infty}$ and $\lim _{n}$ for $\lim _{n \rightarrow \infty}$.

The definitions given below may be conveniently found in [1-3].

A complete metric linear space is called a Frèchet space. Let $X$ be a linear subspace of $s$ such that $X$ is a Frèchet space with continuous coordinate projections. Then we say that $X$ is an FK space. If the metric of an FK space is given by a complete norm, then we say that $X$ is a BK space.

We say that an FK space $X$ has $\mathrm{AK}$, or has the AK property, if $\left(e_{k}\right)$, the sequence of unit vectors, is a Schauder basis for $X$.

A sequence space $X$ is called

(i) normal (or solid) if $y=\left(y_{k}\right) \in X$ whenever $\left|y_{k}\right| \leq\left|x_{k}\right|, k \geq 1$, for some $x=\left(x_{k}\right) \in X$,

(ii) monotone if it contains the canonical preimages of all its stepspaces,

(iii) sequence algebra if $x y=\left(x_{k} y_{k}\right) \in X$ whenever $x=\left(x_{k}\right), y=\left(y_{k}\right) \in X$,

(iv) convergence free when, if $x=\left(x_{k}\right)$ is in $X$ and if $y_{k}=0$ whenever $x_{k}=0$, then $y=\left(y_{k}\right)$ is in $X$.

The idea of dual sequence spaces was introduced by Köthe and Toeplitz [4] whose main results concerned $\alpha$-duals; the $\alpha$-dual of $X \subset s$ being defined as

$$
X^{\alpha}=\left\{a=\left(a_{k}\right) \in s: \sum_{k}\left|a_{k} x_{k}\right|<\infty \text { for all } x=\left(x_{k}\right) \in X\right\} .
$$

@ 2013 Bhardwaj and Gupta; licensee Springer. This is an Open Access article distributed under the terms of the Creative Commons Attribution License (http://creativecommons.org/licenses/by/2.0), which permits unrestricted use, distribution, and reproduction in any medium, provided the original work is properly cited. 
In the same paper [4], they also introduced another kind of dual, namely, the $\beta$-dual (see [5] also, where it is called the $g$-dual by Chillingworth) defined as

$$
X^{\beta}=\left\{a=\left(a_{k}\right) \in s: \sum_{k} a_{k} x_{k} \text { converges for all } x=\left(x_{k}\right) \in X\right\} .
$$

Obviously, $\phi \subset X^{\alpha} \subset X^{\beta}$, where $\phi$ is the well-known sequence space of finitely non-zero scalar sequences. Also, if $X \subset Y$, then $Y^{\eta} \subset X^{\eta}$ for $\eta=\alpha, \beta$. For any sequence space $X$, we denote $\left(X^{\delta}\right)^{\eta}$ by $X^{\delta \eta}$, where $\delta, \eta=\alpha$ or $\beta$. It is clear that $X \subset X^{\eta \eta}$, where $\eta=\alpha$ or $\beta$.

For a sequence space $X$, if $X=X^{\alpha \alpha}$ then $X$ is called a Köthe space or a perfect sequence space.

A sequence space $x=\left(x_{k}\right)$ of complex numbers is said to be $(C, 1)$ summable (or Cesàro summable of order 1) to $\ell \in \mathbb{C}$ if $\lim _{k} \sigma_{k}=\ell$, where $\sigma_{k}=\frac{1}{k} \sum_{i=1}^{k} x_{i}$. By $C_{1}$ we shall denote the linear space of all $(C, 1)$ summable sequences of complex numbers over $\mathbb{C}$, i.e.,

$$
C_{1}=\left\{x=\left(x_{k}\right) \in s:\left(\frac{1}{k} \sum_{i=1}^{k} x_{i}\right) \in c\right\} .
$$

It is easy to see that $C_{1}$ is a BK space normed by

$$
\|x\|=\sup _{k} \frac{1}{k}\left|\sum_{i=1}^{k} x_{i}\right|, \quad x=\left(x_{k}\right) \in C_{1} .
$$

The notion of difference sequence space was introduced by Kizmaz [6] in 1981 as follows:

$$
X(\Delta)=\left\{x=\left(x_{k}\right) \in s:\left(\Delta x_{k}\right) \in X\right\}
$$

for $X=\ell_{\infty}, c, c_{0}$; where $\Delta x_{k}=x_{k}-x_{k+1}$ for all $k \in \mathbb{N}$ (the set of natural numbers). For a detailed account of difference sequence spaces, one may refer to [7-18] where many more references can be found.

\section{Motivation and introduction}

During the last 32 years, a large amount of work has been carried out by many mathematicians regarding various generalizations of difference sequence spaces of Kizmaz. Keeping aside some exceptions (see, for instance, $[7,8]$ ), in most of these works, the underlying spaces have remained the same, i.e., $\ell_{\infty}, c$ and $c_{0}$. In the present work, we take the opportunity to introduce a difference sequence space with underlying space as $C_{1}$.

We observe that

(i) $C_{1} \nsubseteq \nsubseteq c(\Delta)$ as $\left((-1)^{k}\right) \in C_{1}$ but $\left((-1)^{k}\right) \notin c(\Delta)$,

(ii) $c(\Delta) \nsubseteq C_{1}$ as $(k) \in c(\Delta)$ but $(k) \notin C_{1}$, and

(iii) $c \subset c(\Delta) \cap C_{1}$.

Thus the sequence spaces $C_{1}$ and $c(\Delta)$ overlap but do not contain each other. Similarly, $C_{1}$ and $\ell_{\infty}$ also overlap without containing each other as is clear from the fact that $C_{1} \nsubseteq \ell_{\infty}$, $\ell_{\infty} \nsubseteq C_{1}$ and $c \subset C_{1} \cap \ell_{\infty}$. Note that the sequence $\left((-1)^{k-1} \sqrt{k}\right)$ is $(C, 1)$ summable but not bounded, whereas the sequence $x=\left(x_{k}\right)$ given by $x_{1}=1, x_{2}=0$ and

$$
x_{k}= \begin{cases}1, & \text { if } 2^{i-1}<k \leq 3\left(2^{i-2}\right)(i=2,3, \ldots) ; \\ 0, & \text { otherwise }\end{cases}
$$


is bounded but not $(C, 1)$ summable. This has motivated the authors to look for a new sequence space which properly includes the spaces $C_{1}, c(\Delta)$ and $\ell_{\infty}$.

We now introduce a sequence space $C_{1}(\Delta)$, Cesàro summable difference sequence space, as follows:

$$
C_{1}(\Delta)=\left\{x=\left(x_{k}\right) \in s:\left(\Delta x_{k}\right) \in C_{1}\right\}
$$

The overall picture regarding inclusions among the already existing spaces $\ell_{\infty}, c, c_{0}, C_{1}$, $\ell_{\infty}(\Delta), c(\Delta), c_{0}(\Delta)$ and the newly introduced space $C_{1}(\Delta)$ is as shown below:



In this paper we show that $C_{1}(\Delta)$ strictly includes the spaces $c_{0}(\Delta)$ and $c(\Delta)$ but overlaps with $\ell_{\infty}(\Delta)$. It is shown that the newly introduced space $C_{1}(\Delta)$ is an inseparable BK space which does not possess any of the following: AK property, monotonicity, normality and perfectness. The Köthe-Toeplitz duals of $C_{1}(\Delta)$ are computed, and as an application, the matrix classes $\left(C_{1}(\Delta), \ell_{\infty}\right),\left(C_{1}(\Delta), c ; P\right)$ and $\left(C_{1}(\Delta), c_{0}\right)$ are also characterized.

\section{Inclusion theorems and topological properties of $C_{1}(\Delta)$}

We begin with elementary inclusion theorems justifying that $C_{1}(\Delta)$ is much wider than $\ell_{\infty}, C_{1}$ and $c(\Delta)$.

Theorem $3.1 \ell_{\infty} \subset C_{1}(\Delta)$, the inclusion being strict.

Proof Let $x=\left(x_{k}\right) \in \ell_{\infty}$. Then there exists $M>0$ such that $\left|x_{1}-x_{k+1}\right| \leq M$ for all $k \geq 1$, and so $\frac{1}{k} \sum_{i=1}^{k} \Delta x_{i} \rightarrow 0$ as $k \rightarrow \infty$. For strict inclusion, observe that $(k) \in C_{1}(\Delta)$ but $(k) \notin \ell_{\infty}$.

Theorem 3.2 $C_{1} \subset C_{1}(\Delta)$, the inclusion being strict.

Proof For $x=\left(x_{k}\right) \in C_{1}$, we have $\lim _{k} \frac{1}{k} x_{k}=0$, and so $\frac{1}{k} \sum_{i=1}^{k} \Delta x_{i} \rightarrow 0$ as $k \rightarrow \infty$. Inclusion is strict in view of the example cited in Theorem 3.1.

Theorem $3.3 c(\Delta) \subset C_{1}(\Delta)$, the inclusion being strict.

Proof Inclusion is obvious since $c \subset C_{1}$. To see that the inclusion is strict, consider the sequence $x=\left(x_{k}\right)=(1,2,1,2,1,2, \ldots)$.

Remark 3.4 Let $X$ and $Y$ be sequence spaces. If $X \nsubseteq Y$, then $X(\Delta) \nsubseteq Y(\Delta)$. 
Proof Since $X \nsubseteq Y$, there is a sequence $x=\left(x_{k}\right) \in X$ such that $x \notin Y$. Consider the sequence $y=\left(y_{k}\right)=\left(0,-x_{1},-x_{1}-x_{2},-x_{1}-x_{2}-x_{3}, \ldots\right)$. Then $y \in X(\Delta)$ but $y \notin Y(\Delta)$.

Remark 3.5 We have already observed that $C_{1} \nsubseteq \ell_{\infty}$ and $\ell_{\infty} \nsubseteq C_{1}$, so by Remark 3.4, it follows that neither $C_{1}(\Delta) \subseteq \ell_{\infty}(\Delta)$ nor $\ell_{\infty}(\Delta) \subseteq C_{1}(\Delta)$. Also, we have $c(\Delta) \subset C_{1}(\Delta) \cap$ $\ell_{\infty}(\Delta)$. In view of this and Theorem 3.3 , we can say that $C_{1}(\Delta)$ strictly includes $c(\Delta)$ and hence $c_{0}(\Delta)$ but overlaps with $\ell_{\infty}(\Delta)$.

We now study the linear topological structure of $C_{1}(\Delta)$.

Theorem 3.6 $C_{1}(\Delta)$ is a BK space normed by

$$
\|x\|_{\Delta}=\left|x_{1}\right|+\sup _{k} \frac{1}{k}\left|\sum_{i=1}^{k} \Delta x_{i}\right|, \quad x=\left(x_{k}\right) \in C_{1}(\Delta) .
$$

The proof is a routine verification by using 'standard' techniques and hence is omitted.

Theorem $3.7 C_{1}(\Delta)$ is not separable.

Proof Let $A$ be the set of all sequences $x_{a}, x_{b}, \ldots$, where

$$
x_{a}=(k+a)_{k}=(1+a, 2+a, \ldots), \quad x_{b}=(k+b)_{k}=(1+b, 2+b, \ldots), \quad \ldots
$$

with $|a-b|>\frac{1}{2} ; a, b \in \mathbb{R}$. Clearly, $A \subset C_{1}(\Delta)$ and $A$ is uncountable. Let $D$ be any dense set in $C_{1}(\Delta)$.

Define a map $f: A \rightarrow D$ as follows:

Let $x_{a} \in A \subset C_{1}(\Delta)$. As $D$ is dense in $C_{1}(\Delta)$, so there exists some $z_{x_{a}} \in D$ such that $\| x_{a}-$ $z_{x_{a}} \|_{\Delta}<\frac{1}{4}$.

We set $f\left(x_{a}\right)=z_{x_{a}}$.

For $x_{a}, x_{b} \in A$, we have

$$
\begin{aligned}
\left\|x_{a}-x_{b}\right\|_{\Delta} & =|(1+a)-(1+b)|+\sup _{k} \frac{1}{k}\left|\sum_{i=1}^{k} \Delta\left(x_{a}-x_{b}\right)_{i}\right| \\
& \geq|a-b| \\
& >\frac{1}{2}
\end{aligned}
$$

Now

$$
\begin{aligned}
\left\|z_{x_{a}}-x_{b}\right\|_{\Delta} & \geq\left\|x_{a}-x_{b}\right\|_{\Delta}-\left\|x_{a}-z_{x_{a}}\right\|_{\Delta} \\
& >\frac{1}{2}-\frac{1}{4}=\frac{1}{4}
\end{aligned}
$$

and already we have $\left\|x_{b}-z_{x_{b}}\right\|_{\Delta}<\frac{1}{4}$, therefore $z_{x_{a}} \neq z_{x_{b}}$. Hence $f$ is one-to-one. As $f(A) \subset D$ so $D$ is uncountable. Thus, $C_{1}(\Delta)$ has no countable dense set.

Corollary $3.8 C_{1}(\Delta)$ does not have a Schauder basis. 
The result follows from the fact that if a normed space has a Schauder basis, then it is separable.

Corollary 3.9 $C_{1}(\Delta)$ does not have the AK property.

Theorem 3.10 $C_{1}(\Delta)$ is not normal (solid) and hence neither perfect nor convergence free.

Proof Taking $x=\left(x_{k}\right)=(k-1)$ and $y=\left(y_{k}\right)=\left((-1)^{k}(k-1)\right)$, we see that $x \in C_{1}(\Delta)$ but $y \notin$ $C_{1}(\Delta)$ although $\left|y_{k}\right| \leq\left|x_{k}\right|, k \geq 1$ and so $C_{1}(\Delta)$ is not normal. It is well known [1] that every perfect space, and also every convergence free space, is normal and consequently $C_{1}(\Delta)$ is neither perfect nor convergence free.

Theorem 3.11 $C_{1}(\Delta)$ is neither monotone nor a sequence algebra.

Proof Take $x=\left(x_{k}\right)=(k) \in C_{1}(\Delta)$. Consider $y=\left(y_{k}\right)$ where

$$
y_{k}= \begin{cases}x_{k}, & \text { if } k \text { is odd } \\ 0, & \text { if } k \text { is even }\end{cases}
$$

i.e., $y=(1,0,3,0,5, \ldots)$. Then $\left(\Delta y_{k}\right)=(1,-3,3,-5,5, \ldots)$ and so $\left(\Delta y_{k}\right) \notin C_{1}$, i.e., $\left(y_{k}\right) \notin C_{1}(\Delta)$ and hence $C_{1}(\Delta)$ is not monotone. To see that $C_{1}(\Delta)$ is not a sequence algebra, take $x=$ $y=(k)$ and observe that $x, y \in C_{1}(\Delta)$ but $x y=\left(k^{2}\right) \notin C_{1}(\Delta)$.

\section{Köthe-Toeplitz duals of $C_{1}(\Delta)$}

In this section we compute the Köthe-Toeplitz duals of $C_{1}(\Delta)$ and show that $C_{1}(\Delta)$ is not perfect.

\section{Theorem 4.1}

$$
\left[C_{1}(\Delta)\right]^{\alpha}=\left\{a=\left(a_{k}\right): \sum_{k} k\left|a_{k}\right|<\infty\right\}=D_{1}
$$

Proof Let $a=\left(a_{k}\right) \in D_{1}$. For any $x=\left(x_{k}\right) \in C_{1}(\Delta)$, we have $\left(\frac{1}{k} \sum_{i=1}^{k} \Delta x_{i}\right) \in c$, i.e., $\left(\frac{1}{k}\left(x_{1}-\right.\right.$ $\left.\left.x_{k+1}\right)\right) \in c$ and so there exists some $M>0$ such that $\left|x_{k}\right| \leq M(k-1)+x_{1}$ for $k \geq 1$ and hence $\sup _{k} k^{-1}\left|x_{k}\right|<\infty$, which implies that

$$
\sum_{k}\left|a_{k} x_{k}\right|=\sum_{k}\left(k\left|a_{k}\right|\right)\left(k^{-1}\left|x_{k}\right|\right)<\infty
$$

Thus, $a=\left(a_{k}\right) \in\left[C_{1}(\Delta)\right]^{\alpha}$.

Conversely, let $a=\left(a_{k}\right) \in\left[C_{1}(\Delta)\right]^{\alpha}$. Then $\sum_{k}\left|a_{k} x_{k}\right|<\infty$ for all $x=\left(x_{k}\right) \in C_{1}(\Delta)$. Taking $x_{k}=k$ for all $k \geq 1$, we have $x=\left(x_{k}\right) \in C_{1}(\Delta)$ whence $\sum_{k} k\left|a_{k}\right|<\infty$.

Remark 4.2 It is well known $[6,16]$ that $\left[c_{0}(\Delta)\right]^{\alpha}=[c(\Delta)]^{\alpha}=\left[\ell_{\infty}(\Delta)\right]^{\alpha}=D_{1}$, so we conclude that $\left[c_{0}(\Delta)\right]^{\alpha}=[c(\Delta)]^{\alpha}=\left[\ell_{\infty}(\Delta)\right]^{\alpha}=\left[C_{1}(\Delta)\right]^{\alpha}$, i.e., the $\alpha$-duals of $c_{0}(\Delta), c(\Delta), \ell_{\infty}(\Delta)$ and $C_{1}(\Delta)$ coincide. 


\section{Theorem 4.3}

$$
\left[C_{1}(\Delta)\right]^{\alpha \alpha}=\left\{a=\left(a_{k}\right): \sup _{k} k^{-1}\left|a_{k}\right|<\infty\right\}=D_{2}
$$

Proof Taking $m=1$ and $X=c$ in [12, Theorem 2.13], we have $[c(\Delta)]^{\alpha \alpha}=\left\{a=\left(a_{k}\right)\right.$ : $\left.\sup _{k} k^{-1}\left|a_{k}\right|<\infty\right\}$ and the result follows in view of Remark 4.2.

Corollary 4.4 $C_{1}(\Delta)$ is not perfect.

The proof follows at once when we observe that the sequence $\left((-1)^{k}(k-1)\right) \in\left[C_{1}(\Delta)\right]^{\alpha \alpha}$ but does not belong to $C_{1}(\Delta)$.

\section{Theorem 4.5}

$$
\left[C_{1}(\Delta)\right]^{\beta}=\left\{a=\left(a_{k}\right): \sum_{k} k\left|a_{k}\right|<\infty\right\}=D_{3} .
$$

Proof Let $a=\left(a_{k}\right) \in D_{3}$ and $x=\left(x_{k}\right) \in C_{1}(\Delta)$. Then $\left(\frac{1}{k} \sum_{i=1}^{k} \Delta x_{i}\right) \in c$. For $n \in \mathbb{N}$, we have

$$
\sum_{k=1}^{n} a_{k} x_{k}=-\sum_{k=2}^{n}(k-1) a_{k}\left(\frac{1}{k-1} \sum_{i=1}^{k-1} \Delta x_{i}\right)+x_{1} \sum_{k=1}^{n} a_{k} .
$$

Obviously, $\left(a_{k}\right)$ and $\left((k-1) a_{k}\right) \in \ell_{1}$. We define $y=\left(y_{k}\right)$ by $y_{1}=0$ and $y_{k}=\frac{1}{k-1} \sum_{i=1}^{k-1} \Delta x_{i}$ for all $k \geq 2$. Then $y \in c$ and since $c^{\alpha}=\ell_{1}$, the series $\sum_{k=2}^{\infty}(k-1) a_{k}\left(\frac{1}{k-1} \sum_{i=1}^{k-1} \Delta x_{i}\right)$ converges absolutely.

Conversely, if $a=\left(a_{k}\right) \in\left[C_{1}(\Delta)\right]^{\beta}$, then $\sum_{k} a_{k} x_{k}$ converges for all $x=\left(x_{k}\right) \in C_{1}(\Delta)$. In particular, taking $x_{k}=1$ for all $k$, we have $\sum_{k} a_{k}$ converges and so $\sum_{k=2}^{\infty}(k-1) \times$ $a_{k}\left(\frac{1}{k-1} \sum_{i=1}^{k-1} \Delta x_{i}\right)$ converges for all $x=\left(x_{k}\right) \in C_{1}(\Delta)$. Since $x=\left(x_{k}\right) \in C_{1}(\Delta)$ if and only if $y=\left(\frac{1}{k} \sum_{i=1}^{k} \Delta x_{i}\right) \in c$, we have $\left((k-1) a_{k}\right) \in c^{\alpha}$.

Corollary 4.6 $\left[c_{0}(\Delta)\right]^{\alpha}=[c(\Delta)]^{\alpha}=\left[\ell_{\infty}(\Delta)\right]^{\alpha}=\left[C_{1}(\Delta)\right]^{\alpha}=\left[C_{1}(\Delta)\right]^{\beta}$.

\section{Matrix maps}

Finally, we characterize certain matrix classes. For any complex infinite matrix $A=\left(a_{n k}\right)$, we shall write $A_{n}=\left(a_{n k}\right)_{k \in \mathbb{N}}$ for the sequence in the $n$th row of $A$. If $X, Y$ are any two sets of sequences, we denote by $(X, Y)$ the class of all those infinite matrices $A=\left(a_{n k}\right)$ such that the series $A_{n}(x)=\sum_{k} a_{n k} x_{k}$ converges for all $x=\left(x_{k}\right) \in X(n=1,2, \ldots)$ and the sequence $A x=\left(A_{n} x\right)_{n \in \mathbb{N}}$ is in $Y$ for all $x \in X$.

The following theorem is well known.

Theorem 5.1 [3, p.219] Let $X$ and $Y$ be BK spaces and suppose that $A=\left(a_{n k}\right)$ is an infinite matrix such that $\left(\sum_{k} a_{n k} x_{k}\right)_{n \in \mathbb{N}} \in Y$ for each $x \in X$, i.e., $A \in(X, Y)$, then $A: X \rightarrow Y$ is a bounded linear operator.

Theorem 5.2 $A \in\left(C_{1}(\Delta), \ell_{\infty}\right)$ if and only if $\sup _{n} \sum_{k=2}^{\infty}(k-1)\left|a_{n k}\right|<\infty$. 
Proof Suppose that $\sup _{n} \sum_{k=2}^{\infty}(k-1)\left|a_{n k}\right|<\infty$ and $x=\left(x_{k}\right) \in C_{1}(\Delta)$. Proceeding as in Theorem 4.5 , we have $\sum_{k=2}^{\infty}\left|a_{n k} \sum_{i=1}^{k-1} \Delta x_{i}\right|<\infty$.

For $m \in \mathbb{N}$,

$$
\sum_{k=1}^{m} a_{n k} x_{k}=-\sum_{k=1}^{m} a_{n k}\left(\sum_{i=1}^{k-1} \Delta x_{i}\right)+x_{1} \sum_{k=1}^{m} a_{n k}
$$

which yields the absolute convergence of $\sum_{k} a_{n k} x_{k}$ for each $n \in \mathbb{N}$, and finally we have

$$
\left|\sum_{k} a_{n k} x_{k}\right| \leq\left(\sup _{k \geq 2}\left|\frac{1}{k-1} \sum_{i=1}^{k-1} \Delta x_{i}\right|\right)\left(\sup _{n} \sum_{k=2}^{\infty}(k-1)\left|a_{n k}\right|\right)+x_{1} \sup _{n} \sum_{k}(k-1)\left|a_{n k}\right|
$$

for all $n \in \mathbb{N}$.

Conversely, by Theorem 5.1, we have

$$
\left|\sum_{k} a_{n k} x_{k}\right|=\left|A_{n}(x)\right| \leq \sup _{n}\left|A_{n}(x)\right|=\|A x\|_{\infty} \leq\|A\|\|x\|_{\Delta}
$$

for each $n \in \mathbb{N}$ and $x=\left(x_{k}\right) \in C_{1}(\Delta)$.

Choose any $n \in \mathbb{N}$ and any $r \in \mathbb{N}$ and define

$$
x_{k}= \begin{cases}(k-1) \operatorname{sgn} a_{n k}, & \text { if } 1<k \leq r \\ 0, & \text { otherwise. }\end{cases}
$$

Then $x=\left(x_{k}\right) \in c \subset C_{1}(\Delta)$ with $\|x\|_{\Delta}=1$. Inserting this value of $x=\left(x_{k}\right)$ in (5.1), we have

$$
\sum_{k=2}^{r}(k-1)\left|a_{n k}\right| \leq\|A\|
$$

Letting $r \rightarrow \infty$ and noting that (5.2) holds for every $n \in \mathbb{N}$, we are through.

Remark 5.3 If $x=\left(x_{k}\right) \in C_{1}(\Delta)$, then there exists some $\ell \in \mathbb{C}$ such that $\lim _{k} \frac{1}{k} \sum_{i=1}^{k} \Delta x_{i}=\ell$. We shall call $\ell$ the $C_{1}(\Delta)$ limit of the sequence $\left(x_{k}\right)$ and by $\left(C_{1}(\Delta), c ; P\right)$ we shall denote that subset of $\left(C_{1}(\Delta), c\right)$ for which $C_{1}(\Delta)$ limits are preserved.

Theorem 5.4 $A \in\left(C_{1}(\Delta), c ; P\right)$ if and only if

(i) $\sup _{n} \sum_{k=2}^{\infty}(k-1)\left|a_{n k}\right|<\infty$,

(ii) $\lim _{n} \sum_{k}(k-1) a_{n k}=-1$,

(iii) $\lim _{n} a_{n k}=0$ for each $k$,

(iv) $\lim _{n} \sum_{k} a_{n k}=0$.

Proof Let the conditions (i)-(iv) hold and suppose that $x=\left(x_{k}\right) \in C_{1}(\Delta)$ with $\lim _{k} \frac{1}{k} \times$ $\sum_{i=1}^{k} \Delta x_{i}=\ell$. It is implicit in (i) that, for each $n \in \mathbb{N}, \sum_{k}(k-1)\left|a_{n k}\right|$ converges. It follows that $\sum_{k=2}^{\infty}(k-1) a_{n k}\left(\frac{1}{k-1} \sum_{i=1}^{k-1} \Delta x_{i}\right)$ converges, whence

$$
\sum_{k} a_{n k} x_{k}=-\sum_{k=2}^{\infty}(k-1) a_{n k}\left(\frac{1}{k-1} \sum_{i=1}^{k-1} \Delta x_{i}-\ell\right)-\ell \sum_{k}(k-1) a_{n k}+x_{1} \sum_{k} a_{n k} .
$$

Let $\epsilon_{k}=\frac{1}{k} \sum_{i=1}^{k} \Delta x_{i}-\ell, H=\sup _{k}\left|\epsilon_{k}\right|$ and $M=\sup _{n} \sum_{k}(k-1)\left|a_{n k}\right|$. 
Then, for any $p \in \mathbb{N}$, we have

$$
\left|\sum_{k=2}^{\infty}(k-1) a_{n k}\left(\frac{1}{k-1} \sum_{i=1}^{k-1} \Delta x_{i}-\ell\right)\right| \leq H \sum_{k=2}^{p}(k-1)\left|a_{n k}\right|+M \sup _{k>p}\left|\epsilon_{k-1}\right|
$$

and hence

$$
\underset{n}{\limsup }\left|\sum_{k=2}^{\infty}(k-1) a_{n k}\left(\frac{1}{k-1} \sum_{i=1}^{k-1} \Delta x_{i}-\ell\right)\right| \leq M \sup _{k>p}\left|\epsilon_{k-1}\right| .
$$

Letting $p \rightarrow \infty$, we have $\sum_{k=2}^{\infty}(k-1) a_{n k}\left(\frac{1}{k-1} \sum_{i=1}^{k-1} \Delta x_{i}-\ell\right) \rightarrow 0$ as $n \rightarrow \infty$. Making use of this and also of (ii) and (iv) in (5.3), we get the result.

Conversely, let $A \in\left(C_{1}(\Delta), c ; P\right)$. Then $\left(\sum_{k} a_{n k} x_{k}\right)_{n \in \mathbb{N}} \in c$ for all $x=\left(x_{k}\right) \in C_{1}(\Delta)$. By the same argument as in Theorem 5.2, we have $\sup _{n} \sum_{k=2}^{\infty}(k-1)\left|a_{n k}\right|<\infty$. Taking $x=e_{k} \in$ $C_{1}(\Delta)$, we get $\left(a_{n k}\right)_{n \in \mathbb{N}} \in c$ with $\lim _{n} a_{n k}=0$ for each $k$. Also, for $x=(k-1)$, we have $\left(\sum_{k}(k-1) a_{n k}\right)_{n \in \mathbb{N}} \in c$ with $\lim _{n} \sum_{k}(k-1) a_{n k}=-1$, and finally $x=(1,1,1, \ldots) \in C_{1}(\Delta)$ yields $\lim _{n} \sum_{k} a_{n k}=0$.

Theorem 5.5 $A \in\left(C_{1}(\Delta), c_{0}\right)$ if and only if

(i) $\sup _{n} \sum_{k=2}^{\infty}(k-1)\left|a_{n k}\right|<\infty$,

(ii) $\lim _{n} \sum_{k}(k-1) a_{n k}=0$,

(iii) $\lim _{n} a_{n k}=0$ for each $k$,

(iv) $\lim _{n} \sum_{k} a_{n k}=0$.

\section{Competing interests}

The authors declare that they have no competing interests.

\section{Authors' contributions}

VKB and SG contributed equally. All authors read and approved the final manuscript.

\section{Author details}

'Department of Mathematics, Kurukshetra University, Kurukshetra, 136119, India. ${ }^{2}$ Department of Mathematics, Arya PG College, Panipat, 132103, India.

\section{Acknowledgements}

The authors are grateful to the referee for his/her valuable comments and suggestions, which have improved the presentation of the paper.

Received: 15 March 2013 Accepted: 17 June 2013 Published: 5 July 2013

\section{References}

1. Cooke, RG: Infinite Matrices and Sequence Spaces. Macmillan \& Co., London (1950)

2. Kamthan, PK, Gupta, M: Sequence Spaces and Series. Dekker, New York (1981)

3. Maddox, IJ: Elements of Functional Analysis, 2nd edn. Cambridge University Press, Cambridge (1988)

4. Köthe, G, Toeplitz, O: Lineare Räume mit unendlich vielen Koordinaten und Ringe unendlicher Matrizen. J. Reine Angew. Math. 171, 193-226 (1934)

5. Chillingworth, HR: Generalized 'dual' sequence spaces. Ned. Akad. Wet. Indag. Math. 20, 307-315 (1958)

6. Kizmaz, H: On certain sequence spaces. Can. Math. Bull. 24(2), 169-176 (1981)

7. Altay, B, Başar, F: The fine spectrum and the matrix domain of the difference operator $\Delta$ on the sequence space $\ell_{p}$. Commun. Math. Anal. 2(2), 1-11 (2007)

8. Başar, F, Altay, B: On the space of sequences of $p$-bounded variation and related matrix mappings. Ukr. Math. J. 55(1), 136-147 (2003)

9. Bektaş, ÇA, Et, M, Çolak, R: Generalized difference sequence spaces and their dual spaces. J. Math. Anal. Appl. 292, 423-432 (2004)

10. Bhardwaj, VK, Bala, I: Generalized difference sequence space defined by $\left|\bar{N}, p_{k}\right|$ summability and an Orlicz function in seminormed space. Math. Slovaca 60(2), 257-264 (2010)

11. Çolak, R: On some generalized sequence spaces. Commun. Fac. Sci. Univ. Ank. Ser. A1 Math. Stat. 38, 35-46 (1989) 
12. Et, M, Çolak, R: On some generalized difference sequence spaces. Soochow J. Math. 21(4), $377-386$ (1995)

13. Et, M: On some generalized Cesàro difference sequence spaces. Istanb. Üniv. Fen Fak. Mat. Derg. 55/56, 221-229 $(1996 / 97)$

14. Et, M: Spaces of Cesàro difference sequences of order $\Delta^{r}$-defined by a modulus function in a locally convex space. Taiwan. J. Math. 10(4), 865-879 (2006)

15. Et, M: Generalized Cesàro difference sequence spaces of non-absolute type involving lacunary sequences. Appl. Math. Comput. 219(17), 9372-9376 (2013)

16. Malkowsky, E, Parashar, SD: Matrix transformations in spaces of bounded and convergent difference sequences of order m. Analysis 17(1), 87-97 (1997)

17. Malkowsky, E, Mursaleen, M, Suantai, S: The dual spaces of sets of difference sequences of order $m$ and matrix transformations. Acta Math. Sin. 23(3), 521-532 (2007)

18. Orhan, C: Cesàro difference sequence spaces and related matrix transformations. Commun. Fac. Sci. Univ. Ank. Ser. A1 Math. Stat. 32(8) 55-63 (1983)

doi:10.1186/1029-242X-2013-315

Cite this article as: Bhardwaj and Gupta: Cesàro summable difference sequence space. Journal of Inequalities and Applications 2013 2013:315.

\section{Submit your manuscript to a SpringerOpen ${ }^{\circ}$ journal and benefit from:}

- Convenient online submission

- Rigorous peer review

- Immediate publication on acceptance

- Open access: articles freely available online

- High visibility within the field

- Retaining the copyright to your article 